Portland State University

PDXScholar

Electrical and Computer Engineering Faculty

Publications and Presentations

Electrical and Computer Engineering

$2-1-2020$

Inversion of Head Waves in Ocean Acoustic Ambient

Noise

Jie Li

Shanghai Jiao Tong University, Shanghai

Peter Gerstoft

Marine Physical Laboratory

Martin Siderius

Portland State University, siderius@pdx.edu

Jun Fan

Shanghai Jiao Tong University, Shanghai

Follow this and additional works at: https://pdxscholar.library.pdx.edu/ece_fac

Part of the Electrical and Computer Engineering Commons

Let us know how access to this document benefits you.

Citation Details

Li, J., Gerstoft, P., Siderius, M., \& Fan, J. (2020). Inversion of head waves in ocean acoustic ambient noise. The Journal of the Acoustical Society of America, 147(3), 1752-1761.

This Article is brought to you for free and open access. It has been accepted for inclusion in Electrical and Computer Engineering Faculty Publications and Presentations by an authorized administrator of PDXScholar. Please contact us if we can make this document more accessible: pdxscholar@pdx.edu. 


\title{
Inversion of head waves in ocean acoustic ambient noise
}

\author{
Jie Li, ${ }^{1, a)}$ Peter Gerstoft, ${ }^{2, b)}$ Martin Siderius, ${ }^{3, c)}$ and Jun Fan ${ }^{1}$ \\ ${ }^{1}$ Collaborative Innovation Center for Advanced Ship and Deep-Sea Exploration, State Key Laboratory of Ocean Engineering, \\ Shanghai Jiao Tong University, Shanghai 200240, China \\ ${ }^{2}$ Noiselab, Scripps Institution of Oceanography, University of California San Diego, La Jolla, California 92093-0238, USA \\ ${ }^{3}$ Department of Electrical and Computer Engineering, Portland State University, Portland, Oregon 97201, USA
}

\begin{abstract}
:
The virtual head wave is produced through cross-correlation processing of signals containing the real, acoustic head wave. The virtual head wave has the same phase speed as the head wave, but the travel time is offset, thus the term virtual. The virtual head wave, like the real head wave, propagates in a direction corresponding to the seabed critical angle. The virtual head wave travel time varies with array depth and water column depth. However, in a refracting environment, the travel time is also dependent on the depth-dependent sound speed profile. Previously, the virtual head wave was shown as observable from measurements of ocean ambient noise, and the arrival angle was used to estimate the seabed sound speed. By also using the virtual head wave travel times, it is possible to invert for array depth and water column depth. The previous analysis was limited to the assumption of a Pekeris waveguide, which is a special case of the more realistic refracting waveguide. In this paper, the virtual head wave and the inversion method are considered in environments having refracting sound speeds. The theoretical framework and the inversion method are presented along with illustrative simulations and application to the Boundary'03 data.

(C) 2020 Acoustical Society of America. https://doi.org/10.1121/10.0000925

(Received 20 October 2019; revised 21 February 2020; accepted 29 February 2020; published online 19 March 2020)

[Editor: Nicholas P. Chotiros]

Pages: $1752-1761$
\end{abstract}

\section{INTRODUCTION}

In recent years, the naturally occurring ocean surface noise has been widely used in ocean acoustics, including for ocean tomography, ${ }^{1}$ array element self-localization, ${ }^{2}$ Green's function recovery, ${ }^{3,4}$ seabed properties extraction, ${ }^{5,6}$ and the passive fathometer. ${ }^{7-13}$

The passive fathometer technique ${ }^{7-13}$ uses a vertical array of hydrophones to extract the reflections of surface noise from the seabed by cross correlating endfire beams (i.e., beams steered directly toward the surface and directly toward the seabed at angles of $\pm 90^{\circ}$ ). This processing can determine the distance from the array to the seabed and subbottom interfaces. By generalizing the passive fathometer processing (i.e., cross correlating noise beams at all angles, not just $\pm 90^{\circ}$ ), one can observe a sequence of signals appearing in time at a specific angle. ${ }^{14,15}$ These signals were referred to as being from the "head wave," and the angle corresponded to the seabed critical angle.

In shallow water overlying a fast seabed, there exists a critically refracted wave propagating along the waterseabed interface at the seabed sound speed. In the water column, these waves arrive ahead of other water borne arrivals, and are thus called head waves. Head waves can be excited in a variety of ways such as explosive sources, ${ }^{16,17}$ helicopter noise, ${ }^{18}$ and ocean surface noise. ${ }^{15}$ In a Pekeris waveguide, their amplitude decays as $r^{-1 / 2} L^{-3 / 2},{ }^{16,19}$ where $r$ is

\footnotetext{
a)Electronic mail: jie_li@sjtu.edu.cn, ORCID: 0000-0003-3066-1590.

${ }^{b)}$ ORCID: 0000-0002-0471-062X.

${ }^{c)}$ ORCID: 0000-0002-3487-6110.
}

the horizontal source-receiver range, and $L$ is the path length along the interface. For long ranges, $L \approx r$, the amplitude decays as $r^{-2}$. In shallow water environments, head waves are usually ignored for long range propagation due to competing factors such as the fast $1 / r^{2}$ geometric spreading, seabed attenuation, and seabed scattering. However, when the range is moderate and the seabed is flat and smooth, head waves are observed and used to infer the seabed sound speed $^{16-19}$ and attenuation. ${ }^{16}$

Here, the head wave is more specifically described as the "virtual head wave" as it has the same phase speed as the head wave, but the travel time is offset. Similar terminology, "virtual refraction," was found in seismology where simulated data with active sound sources distributed near the sea-surface and received on a horizontal array were used to describe this phenomenon. ${ }^{20}$ The passive extraction of the virtual head wave travel times is based on the well-known Green's function retrieval method. ${ }^{21-25}$ To estimate the exact Green's function, theory requires that the receivers are surrounded by sources on a closed surface, ${ }^{25,26}$ however, it is usual for the source aperture to be finite, resulting in the appearance of spurious multiples. ${ }^{22,27}$ The spurious multiples can come from the cross correlation of scattered ${ }^{28}$ and reflected waves. ${ }^{29}$ The virtual head wave is another type of spurious multiple, which is due to the cross correlation of real head waves. ${ }^{15}$

Most research on virtual head waves has focused on the Pekeris waveguide, ${ }^{14,15,20}$ which does not represent many realistic ocean environments. If there is refraction in the water column, rays will bend following Snell's law, thus the head wave angle of arrival will not always be the seabed 
critical angle. In addition to the arrival angle, the travel time of the head wave is also affected by the water-column sound speed profile. Since the virtual head wave is produced by the cross correlation of signals containing the real head wave, its travel time and angle of arrival might also be different from those expected for a Pekeris (non-refracting) waveguide.

This paper will first study the travel time and angle of arrival of the virtual head wave in a refracting waveguide based on ray theory. Further, the virtual head wave travel time (in addition to the angle of arrival) will be used to invert for geometric and environmental parameters. It is shown here that in a refracting waveguide the virtual head wave based inversion method allows for estimates of two parameters (array depth and seabed sound speed), whereas in a non-refracting (i.e., Pekeris) waveguide, three parameters can be determined (array depth, seabed sound speed, and water column depth). The method is illustrated with simulations and applied to acoustic data gathered in a refracting shallow water region of the Mediterranean Sea. Results show that the virtual head wave travel time changes with in-water refraction, and an inverse method can be used to determine the array depth and seabed sound speed.

The organization of this paper is as follows. Section II derives both the virtual head wave theories and inversion methods in refracting and Pekeris waveguides. In Sec. III, simulations are used to verify the results in Sec. II. Section IV demonstrates the inversion method in a refracting waveguide with Boundary'03 data. ${ }^{7,9,15}$

\section{ACOUSTIC INVERSION WITH VIRTUAL HEAD WAVES}

\section{A. Refracting waveguide}

Consider the refracting waveguide shown in Fig. 1(a), where the sound speed in the water column depends on depth, $v=v(z)(0 \leq z \leq H)$, and the sound speed in the seabed is constant, $v_{p}$. Note, to avoid ambiguity, $v\left(H^{-}\right)$ instead of $v(H)$ is used in the following to refer to the sound speed in the water column just above the seabed. For source $S\left(x_{s}, a\right)$ and receiver $r(0, b)(0 \leq a<b \leq H)$ in Fig. 1(b), a ray departing from the source at angle $\theta_{a}$ will refract (bend) in the water column and be received at angle $\theta_{b}$. This refraction is governed by Snell's law,

$$
\begin{aligned}
\theta_{a} & =\arccos \left[v(a) \cos \theta_{p} / v_{p}\right], \\
\theta_{b} & =\arccos \left[v(b) \cos \theta_{p} / v_{p}\right],
\end{aligned}
$$

where $v_{p}$ and $\theta_{p}$ are the sound speed and grazing angle in the seabed, respectively. The horizontal waterborne range covered by the ray is 30,31

$$
\begin{aligned}
x_{a}^{b} & =\cos \theta_{a} \int_{a}^{b} \frac{\mathrm{d} z}{\sqrt{n^{2}(z)-\cos ^{2} \theta_{a}}} \\
& =\int_{a}^{b} \frac{v(z) \cos \theta_{p}}{\sqrt{v_{p}^{2}-v^{2}(z) \cos ^{2} \theta_{p}}} \mathrm{~d} z \\
& =\int_{a}^{b} \frac{s_{p} \cos \theta_{p}}{s_{z}} \mathrm{~d} z,
\end{aligned}
$$

where $n(z)=v(a) / v(z), s_{p}=1 / v_{p}$ is bottom slowness, $s_{z}$ $=\sqrt{s^{2}(z)-s_{p}^{2} \cos ^{2} \theta_{p}}$ is vertical slowness, and $s(z)$ $=1 / v(z)$ is slowness. The travel time along the ray is, ${ }^{30,31}$

$$
\begin{aligned}
t_{a}^{b} & =\frac{1}{v(a)} \int_{a}^{b} \frac{n^{2}(z)}{\sqrt{n^{2}(z)-\cos ^{2} \theta_{a}}} \mathrm{~d} z \\
& =\int_{a}^{b} \frac{v_{p}}{v(z) \sqrt{v_{p}^{2}-v^{2}(z) \cos ^{2} \theta_{p}}} \mathrm{~d} z \\
& =\int_{a}^{b} \frac{s^{2}(z)}{s_{z}} \mathrm{~d} z .
\end{aligned}
$$

(a)

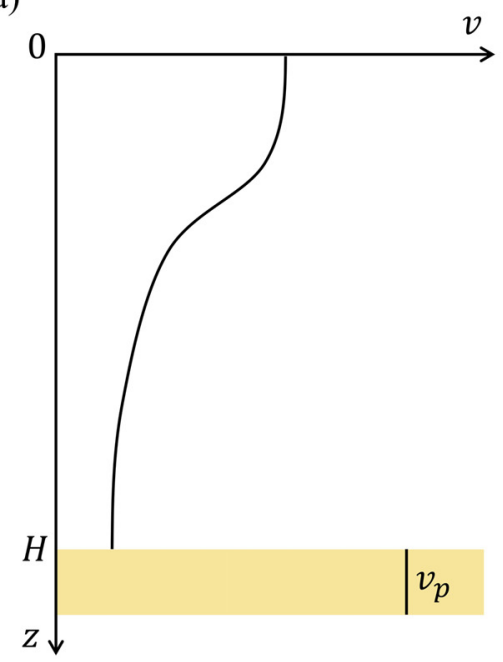

(b)

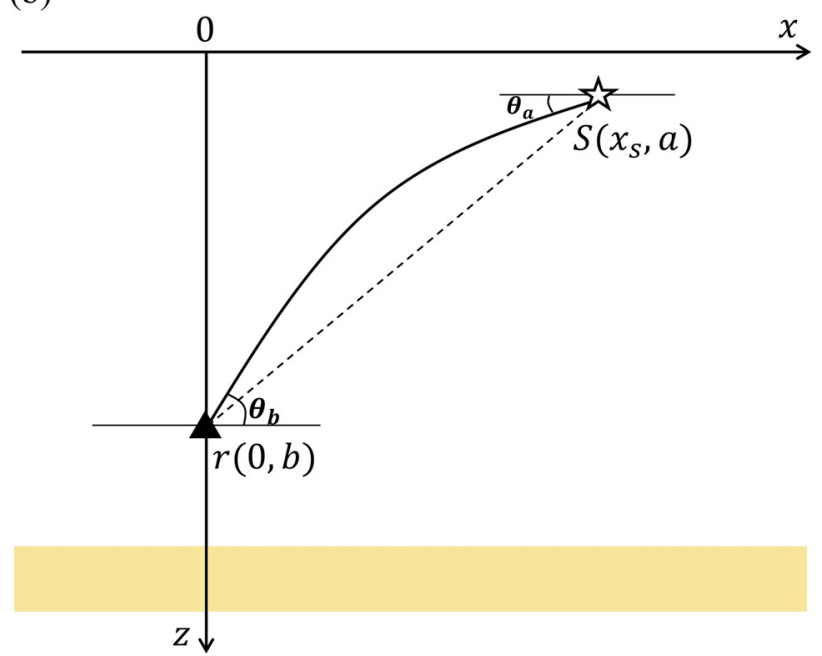

FIG. 1. (Color online) (a) The refracting waveguide model. (b) Definition of coordinate system and geometric quantities. For constant sound speed, the ray is a straight line (dashed), and $\theta_{a}=\theta_{b}$. The thick solid line represents the ray path in the presence of in-water refraction. 


\section{Head waves between source and receiver}

As shown in Fig. 2(a), the head wave from a point source located on a line $S\left(x_{s}, 0\right)\left(x_{s}>X_{c}\right.$, where $X_{c}$ is referred to as the critical offset) is incident on the seabed at the critical angle $\theta_{c}$, travels along the seabed $\left(\theta_{p}=0^{\circ}\right)$, reradiates plane waves into the water, which propagate at $\theta_{c}$, and arrive at the receiver $r_{j}\left(0, z_{j}\right)$ at $\theta_{z_{j}}$. From Eq. (1), $\theta_{c}=\theta_{H^{-}}=\arccos \left[v\left(H^{-}\right) / v_{p}\right], \theta_{z_{j}}=\arccos \left[v\left(z_{j}\right) / v_{p}\right]$. The horizontal range covered by the ray in Fig. 1(b) is therefore simplified from Eq. (2) to Eq. (4),

$$
x_{a}^{b}=\int_{a}^{b} \frac{s_{p}}{s_{z}} \mathrm{~d} z,
$$

where $a$ and $b$ depend on the specific source and receiver path, and $s_{z}=\sqrt{s^{2}(z)-s_{p}^{2}}$. It is useful to work with delay time [see Sec. 4.3 .2 of Ref. 30, also called $\tau(p)$ function]

$$
\tau_{a}^{b}=t_{a}^{b}-s_{p} x_{a}^{b}=\int_{a}^{b} s_{z} \mathrm{~d} z,
$$

where $s_{p}$ is now horizontal slowness.

The geometry does not allow a head wave (propagating at the critical angle) to be received at $r_{j}$ if $x_{s} \leq X_{c}$. Note, apart from the head wave from $S$ to $r_{j}$ shown in Fig. 2(a), head waves can also bounce between the sea surface and seabed and have down-going propagation to $r_{j}{ }^{15}$

The head waves consist of two components: One part is in the water column, and the other part is within the seabed.
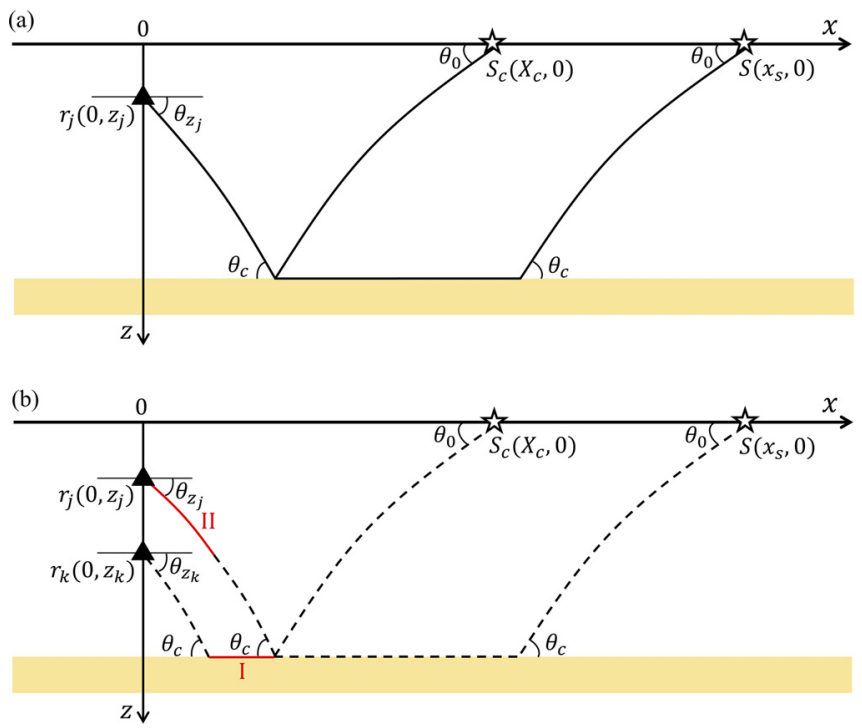

FIG. 2. (Color online) (a) The total reflection between source $S_{c}$ and receiver $r_{j}$, and the head wave between source $S$ and receiver $r_{j}$. Head waves appear when $S$ is beyond the critical offset $X_{c}$ (distance where the incident ray is at the seabed critical angle $\theta_{c}$ ). (b) The virtual head wave between two vertically aligned receivers $r_{j}$ and $r_{k}$ is obtained by cross correlating the total reflection between $S_{c}$ and $r_{j}$ and the head wave between $S_{c}$ and $r_{k}$, or the head waves between $S$ and $r_{j}, r_{k}$. After the cross-correlation processing, the common ray paths between $S$ and $r_{j}, r_{k}$ (dashed lines) disappear, and only ray paths labeled I and II (solid lines) are left.
The travel time of head waves up-going to $r_{j}$ from $S$ is a sum of these two parts,

$$
\begin{aligned}
t_{-}^{j}(m) & =t_{\text {water }}+t_{\text {seabed }} \\
& =(2 m-1) t_{0}^{H}+t_{z_{j}}^{H}+\left[x_{s}-(2 m-1) x_{0}^{H}-x_{z_{j}}^{H}\right] / v_{p} \\
& =(2 m-1) \tau_{0}^{H}+\tau_{z_{j}}^{H}+x_{s} / v_{p},
\end{aligned}
$$

where the subscript "-_" is up-going to $r_{j}$, and $m \geq 1$ is the number of bounces from the bottom interface at depth $H$ between $S$ and $r_{j .}{ }^{30,31}$ Similarly, the travel times of head waves down-going ("+") to $r_{j}$ from $S$ are

$$
\begin{aligned}
t_{+}^{j}(m) & =2 m t_{0}^{H}+t_{0}^{z_{j}}+\left(x_{s}-2 m x_{0}^{H}-x_{0}^{z_{j}}\right) / v_{p} \\
& =2 m \tau_{0}^{H}+\tau_{0}^{z_{j}}+x_{s} / v_{p} .
\end{aligned}
$$

\section{Virtual head waves between vertically aligned receivers}

For vertically aligned receivers $r_{j}\left(0, z_{j}\right)$ and $r_{k}\left(0, z_{k}\right)$ ( $1 \leq j \leq N_{R}, 1 \leq k \leq N_{R}, N_{R}$ is the number of receivers, $\theta_{z_{j}} \approx \theta_{z_{k}}$ ) in Fig. 2(b), assuming that $z_{j}<z_{k}$ and $x_{s}>X_{c}$, the virtual head waves between them are produced by cross correlating the head waves from $S$ to $r_{j}$ and $r_{k}$ or cross correlating total reflections from $S_{c}$ to $r_{j}$ and head waves from $S_{c}$ to $r_{k}$. Note, the head waves and total reflections always propagate at the critical angle, making the cross correlation coherent. The seabed reflections have multiple angles depending on the source-receiver range, making their cross correlation incoherent.

After the cross-correlation processing, the common ray paths between $S$ and $r_{j}, r_{k}$ or between $S_{c}$ and $r_{j}, r_{k}$, represented by the dashed lines, will disappear; thus the virtual head wave travel time equals the travel time differences on ray paths I and II. Therefore, the virtual head wave travel time between $r_{j}$ and $r_{k}$ is the same for sources $S$ and $S_{c}$. Since the source-to-seabed path is canceled through the cross-correlation processing, source localization cannot be determined through inversion of virtual head waves. In the vertical array and passive noise case, the virtual head waves have contributions from noises located on an annulus, where the inner radius is the critical offset, and the external radius is the farthest source-receiver horizontal distance that makes the head waves detectable.

Figure 2(b) only shows the geometry of virtual head waves when $z_{j}<z_{k}$, but the virtual head waves also exist for $z_{j} \geq z_{k}$. Besides, head waves and total reflections are shown up-going to the receivers in Fig. 2(b), and they can also be down-going to the receivers after a surface reflection.

The travel times of virtual head waves between $r_{j}$ and $r_{k}$ are represented as the travel time differences of head waves between $S$ to $r_{j}$ and $S$ to $r_{k}$,

$$
\delta t_{ \pm \pm \pm}^{j k}\left(\Delta_{m}\right)=t_{ \pm}^{j}(m)-t_{ \pm}^{k}(n),
$$

where $n \geq 1$ is the seabed bounce of rays between $S$ and $r_{k}$, $\Delta_{m}=m-n$ is the difference of seabed bounces of rays 
between $S$ to $r_{j}$ and $S$ to $r_{k}$. Inserting Eqs. (6) and (7) into Eq. (8),

$$
\begin{aligned}
& \delta t_{++}^{j k}\left(\Delta_{m}\right)=2 \Delta_{m} \tau_{0}^{H}-\tau_{z_{j}}^{z_{k}}, \\
& \delta t_{--}^{j k}\left(\Delta_{m}\right)=2 \Delta_{m} \tau_{0}^{H}+\tau_{z_{j}}^{z_{k}}, \\
& \delta t_{-+}^{j k}\left(\Delta_{m}\right)=2 \Delta_{m} \tau_{0}^{H}-\tau_{0}^{z_{j}}-\tau_{0}^{z_{k}}, \\
& \delta t_{+-}^{j k}\left(\Delta_{m}\right)=2 \Delta_{m} \tau_{0}^{H}+\tau_{0}^{z_{j}}+\tau_{0}^{z_{k}} .
\end{aligned}
$$

From Eq. (9), the vertical phase speeds of virtual head waves are $\left|d z_{k} / d\left(\delta t_{ \pm \pm}^{j k}\right)\right|=\left|d z_{k} / d\left(\tau_{0}^{z_{k}}\right)\right|=\left|d z_{k} / d\left(\tau_{z_{j}}^{z_{k}}\right)\right|$ $=\left[v^{-2}\left(z_{k}\right)-s_{p}^{2}\right]^{-1 / 2}$, where $\tau_{a}^{b}$ is given by Eq. (5). These are the same as those of head waves, $\left|d z_{j} / d t_{ \pm}^{j}\right|=\left|d z_{j} / d\left(\tau_{0}^{z_{j}}\right)\right|$ $=\left|d z_{j} / d\left(\tau_{z_{j}}^{H}\right)\right|=\left[v^{-2}\left(z_{j}\right)-s_{p}^{2}\right]^{-1 / 2}$, from Eqs. (6) and (7). They represent waves propagating at the critical angle. However, the travel time is offset, thus the term is virtual.

Aligning the virtual head waves by letting $j=k=1$, Eq. (9) becomes

$$
\begin{aligned}
& \delta t_{++}\left(\Delta_{m}\right)=\delta t_{--}\left(\Delta_{m}\right)=2 \Delta_{m} \tau_{0}^{H}, \\
& \delta t_{-+}\left(\Delta_{m}\right)=2 \Delta_{m} \tau_{0}^{H}-2 \tau_{0}^{z_{1}}, \\
& \delta t_{+-}\left(\Delta_{m}\right)=2 \Delta_{m} \tau_{0}^{H}+2 \tau_{0}^{z_{1}} .
\end{aligned}
$$

From Eq. (10), there are four contributions of virtual head waves due to up- and down-going head waves at the receiver. ${ }^{15}$ For a given $\Delta_{m}$, there are three distinct travel times that are periodic in time with $2 \tau_{0}^{H}$. This interval time is not related to array depth or array spacing, since it is only a function of environmental parameters $v(z), v_{p}$, and $H$.

\section{Auto-beam and cross-beam}

The travel times and angles of arrival of the virtual head waves can be estimated using measurements of ocean ambient noise on a vertical line array. ${ }^{15}$ The processing used is a generalization of the passive fathometer to produce auto-beam and cross-beam correlations. When using delay and sum beamforming, the processing is equivalent to the seismic interferometry techniques. ${ }^{15}$

The auto-beam correlations, $C_{--}(\omega, \theta)$ or $C_{++}(\omega, \theta)$, are the auto-correlations between up-going beams $d_{-}(\omega, \theta)=\mathbf{w}_{-}^{H} \mathbf{p}$, or down-going beams $d_{+}(\omega, \theta)=\mathbf{w}_{+}^{H} \mathbf{p}$, while the cross-beam correlations, $C_{-+}(\omega, \theta)$ or $C_{+-}(\omega, \theta)$, are the cross correlations between $d_{-}(\omega, \theta)$ and $d_{+}(\omega, \theta)$ or vice versa,

$$
\begin{aligned}
& C_{--}(\omega, \theta)=d_{-}(\omega, \theta) d_{-}^{H}(\omega, \theta)=\mathbf{w}_{-}^{H} \mathbf{C} \mathbf{w}_{-}, \\
& C_{++}(\omega, \theta)=d_{+}(\omega, \theta) d_{+}^{H}(\omega, \theta)=\mathbf{w}_{-}^{T} \mathbf{C w}_{-}^{*}, \\
& C_{-+}(\omega, \theta)=d_{-}(\omega, \theta) d_{+}^{H}(\omega, \theta)=\mathbf{w}_{-}^{H} \mathbf{C w}_{-}^{*}, \\
& C_{+-}(\omega, \theta)=d_{+}(\omega, \theta) d_{-}^{H}(\omega, \theta)=\mathbf{w}_{-}^{T} \mathbf{C} \mathbf{w}_{-},
\end{aligned}
$$

where $\mathbf{w}_{-}(\omega, \theta)=\left[e^{i \omega z_{1} \sin \theta / v}, \ldots, e^{i \omega z_{N_{R}} \sin \theta / v}\right]^{T}$ and $\mathbf{w}_{+}(\omega, \theta)$ $=\mathbf{w}_{-}^{*}(\omega, \theta)$ are the steering vectors for up- and down-going wave fields, $\mathbf{p}(\omega)=\left[p_{1}(\omega), \ldots, p_{N_{R}}(\omega)\right]^{T}$ is the pressure vector, superscripts $T$ and $H$ represent the transpose and conjugate transpose, respectively. The cross-spectral density matrix $\mathbf{C}$ is estimated from the ensemble average $\mathbf{C}=(1 / L) \sum_{l=1}^{L} \mathbf{p}_{l} \mathbf{p}_{l}^{H}$ of $L$ snapshots of pressure field $\mathbf{p}_{l}$. Equation (11) is transformed to the time domain,

$$
c_{ \pm \pm}(\tau, \theta)=\mathcal{F}^{-1}\left[C_{ \pm \pm}(\omega, \theta)\right]
$$

where $\tau$ is lag time. The virtual head waves appear as the sequences of peaks at the same angles $\theta_{z_{1}}=\arccos \left(v_{z_{1}} / v_{p}\right)$ in all of the time domain correlations in Eq. (12). However, the travel times of virtual head waves are different [Eq. (10)].

Since $c_{-+}(\tau, \theta)$ and $c_{+-}(\tau, \theta)$ contain the same information $\left[c_{-+}(\tau, \theta)=c_{+-}(-\tau, \theta)\right]$, the following inversion method is based on $c_{--}(\tau, \theta), c_{++}(\tau, \theta)$, and $c_{-+}(\tau, \theta)$.

\section{Inversion with auto-beam and cross-beam}

In $c_{--}(\tau, \theta)$ or $c_{++}(\tau, \theta)$, the angle of arrival, $\theta_{z_{1}}$, depends on $z_{1}$ and $v_{p}$, and the travel times, $\delta t_{--}\left(\Delta_{m}\right)$ or $\delta t_{++}\left(\Delta_{m}\right)$, depend on environmental parameters, including $v(z), v_{p}$, and $H$ [Eq. (10)]. It is therefore possible to estimate $v_{p}$ and $z_{1}$ with $v(z), H$, from the measured angle of arrival $\theta_{z_{1}}^{\prime}$, and interval time $T_{\text {int }}^{\prime}$ extracted from either $c_{--}(\tau, \theta)$ or $c_{++}(\tau, \theta)$ by minimizing the cost functions,

$$
\begin{aligned}
Y_{--}\left(z_{1}, v_{p}\right)= & Y_{++}\left(z_{1}, v_{p}\right) \\
= & \left(T_{\text {int }}^{\prime}-2 \tau_{0}^{H}\right)^{2} \\
& +\lambda\left[\theta_{z_{1}}^{\prime}-\arccos \left(v\left(z_{1}\right) / v_{p}\right)\right]^{2},
\end{aligned}
$$

where $\lambda$ is a Lagrange multiplier. We match the interval and angle of arrival from predictions and measurements by a grid search of $z_{1}$ and $v_{p}$.

The virtual head wave travel times from the cross-beam correlation, $\delta t_{-+}\left(\Delta_{m}\right)$, is a function of $v(z), v_{p}, H$, and $z_{1}$. Similarly, it is possible to invert for $v_{p}$ and $z_{1}$ based on $v(z)$, $H, \theta_{z_{1}}^{\prime}$, and $\delta t^{\prime}{ }_{-+}\left(\Delta_{m}\right)$ by finding the minimum of the cost function $Y_{-+}\left(z_{1}, v_{p}\right)$,

$$
\begin{aligned}
Y_{-+}\left(z_{1}, v_{p}\right)= & {\left[\delta t^{\prime}{ }_{-+}(0)-\delta t_{-+}(0)\right]^{2} } \\
& +\left[\delta t^{\prime}-+(1)-\delta t_{-+}(1)\right]^{2} \\
& +\lambda\left[\theta_{z_{1}}^{\prime}-\arccos \left(v\left(z_{1}\right) / v_{p}\right)\right]^{2},
\end{aligned}
$$

where $\delta t_{-+}(0)$ and $\delta t_{-+}(1)$ are the predicted travel times from Eq. (10),

$$
\delta t_{-+}(0)=-2 \tau_{0}^{z_{1}}, \quad \delta t_{-+}(1)=2 \tau_{z_{1}}^{H},
$$

where $\delta t_{-+}(0)$ is affected by the sound speed profile above the array and $v_{p}$, while $\delta t_{-+}(1)$ is affected by the sound speed profile below the array and $v_{p}$.

The cost functions in Eqs. (13) and (14) can all invert for $v_{p}$. However, if $v(z)$ varies slightly with depth, $Y_{-+}$is preferable for finding $z_{1}$ as it is contained in both the travel time and angle contribution (see the Appendix for a detailed proof). In Secs. III and IV, the simulation and experimental 
inversion of $z_{1}$ and $v_{p}$ are based on $Y_{-+}$[Eq. (14)]. We choose $\lambda=10^{-5}$ to balance the two terms in Eq. (14) (assuming $=\left|\delta t_{-+}^{\prime}(0)\right|=\left|\delta t_{-+}^{\prime}(1)\right|=0.02 \mathrm{~s}, \theta_{z_{1}}^{\prime}=10^{\circ}$ ).

\section{B. The Pekeris waveguide}

For the Pekeris waveguide, the sound speed is constant $v_{w}$ in the water column, the rays are straight lines, $\theta_{0}=\theta_{z_{1}}$ $=\theta_{c}=\arccos \left(v_{w} / v_{p}\right)$. The virtual head wave travel times in Eq. (10) are simplified as

$$
\begin{aligned}
& \delta t_{++}\left(\Delta_{m}\right)=\delta t_{--}\left(\Delta_{m}\right)=2 \Delta_{m} H s_{z}, \\
& \delta t_{-+}\left(\Delta_{m}\right)=\left(2 \Delta_{m} H-2 z_{1}\right) s_{z}, \\
& \delta t_{+-}\left(\Delta_{m}\right)=\left(2 \Delta_{m} H+2 z_{1}\right) s_{z},
\end{aligned}
$$

where $s_{z}=\sqrt{v_{w}^{-2}-s_{p}^{2}}$. This virtual head wave travel time is in agreement with a previous study ${ }^{15}$ [Eq. (9)]. Similar to the refracting waveguide, there are four contributions of virtual head waves and three distinct travel times for a given $\Delta_{m}$. The virtual head waves are periodic in time with interval $2 H s_{z}$, which is not related to array depth or array spacing, since it is only a function of $v_{w}, v_{p}$, and $H$.

It is therefore possible to estimate $v_{p}$ and $H$ by finding the minimum function $Y_{--}\left(v_{p}, H\right)$ [or $Y_{++}\left(v_{p}, H\right)$,

$$
\begin{aligned}
Y_{--}\left(v_{p}, H\right)= & Y_{++}\left(v_{p}, H\right) \\
= & \left(T_{\text {int }}^{\prime}-2 H s_{z}\right)^{2} \\
& +\lambda\left[\theta_{c}^{\prime}-\arccos \left(v_{w} / v_{p}\right)\right]^{2},
\end{aligned}
$$

or, invert for $z_{1}, v_{p}$, and $H$ by finding the minimum of the function,

$$
\begin{aligned}
Y_{-+}\left(z_{1}, v_{p}, H\right)= & {\left[\delta t^{\prime}{ }_{-+}(0)-\delta t_{-+}(0)\right]^{2} } \\
& +\left[\delta t^{\prime}-+(1)-\delta t_{-+}(1)\right]^{2} \\
& +\lambda\left[\theta_{c}^{\prime}-\arccos \left(v_{w} / v_{p}\right)\right]^{2},
\end{aligned}
$$

where $\delta t_{-+}(0)$ and $\delta t_{-+}(1)$ are predicted travel times of virtual head waves from Eq. (16),

$$
\delta t_{-+}(0)=-2 z_{1} s_{z}, \quad \delta t_{-+}(1)=2\left(H-z_{1}\right) s_{z} .
$$

Here, $\delta t_{-+}(0)$ is affected by $z_{1}, v_{w}$, and $v_{p}$, and $\delta t_{-+}(1)$ is affected by the distance between the array and seabed $H-z_{1}, v_{w}$, and $v_{p}$.

From Eq. (17), two parameters, $v_{p}$ and $H$, are estimated with the observed interval $T_{\text {inv }}^{\prime}$, angle of arrival $\theta_{c}^{\prime}$, and $v_{w}$. However, when any one of these three parameters $\left(v_{p}, H\right.$, and $v_{w}$ ) is known, the other two can be determined by combining the known parameter with $T_{\text {inv }}^{\prime}$ and $\theta_{c}^{\prime}$.

Similarly, from Eq. (18), three parameters, $z_{1}, v_{p}$, and $H$, are estimated with $\delta t^{\prime}{ }_{-+}(0), \delta t_{-+}^{\prime}(1), \theta_{c}^{\prime}$, and $v_{w}$. However, when any one of these four parameters $\left(z_{1}, v_{p}, H\right.$, and $\left.v_{w}\right)$ is known, the other three can be determined by combining the known parameter with $\delta t_{-+}^{\prime}(0), \delta t_{-+}^{\prime}(1), \theta_{c}^{\prime}$, and $v_{w}$.
In Secs. III and IV, the inversion results of $z_{1}, v_{p}$, and $H$ based on $Y_{-+}$[Eq. (18)] for a Pekeris waveguide will be shown, with $\lambda=10^{-5}$ for both simulation and experimental data.

\section{SIMULATION}

Simulations illustrate the impact of a refracting environment on the virtual head wave in a controllable and known environment. The geometry for the simulations is shown in Fig. 3 and is based on the Boundary'03 experiment ${ }^{7,9,15}$ (described more completely in Sec. IV). To approximate the noise field generated by breaking waves, the simulation uses sources having random amplitude and phase, which are uniformly distributed on an infinite plane close to the surface (represented as stars in Fig. 3). The vertical line array consists of 32 hydrophones with spacing of $0.18 \mathrm{~m}$, and the depth of the first hydrophone is at $z_{1}=73 \mathrm{~m}$ (represented by triangles in Fig. 3). To simulate both the refracting and Pekeris waveguides, two sound speed profiles are considered. The refracting sound speed profile is from the Boundary'03 data, while the Pekeris profile is constant at $1512 \mathrm{~m} / \mathrm{s}$. The seabed is assumed to be a half space with a sound speed of $1541 \mathrm{~m} / \mathrm{s}$, density of $1500 \mathrm{~kg} / \mathrm{m}^{3}$, and attenuation of $0.02 \mathrm{~dB}$ per wavelength. The wavenumber integration code OASES is used to compute the simulated array data. $^{32,33}$ To better represent the measured data (obtain more realistic simulations), an additional step is taken to create random realizations of data that are averaged in the same way as the measurements. To accomplish this, the exact array covariance matrix from the OASES simulation is decomposed using the Cholesky method. ${ }^{34}$ This produces the sample covariance matrix with the following procedure:

(1) Obtain the covariance matrix $\mathbf{C}(\omega)$ from OASES.

(2) Obtain the positive definite lower-triangular matrix $\mathbf{L}$ through Cholesky factorization, $\mathbf{C}(\omega)=\mathbf{L}(\omega) \mathbf{L}^{H}(\omega)$.

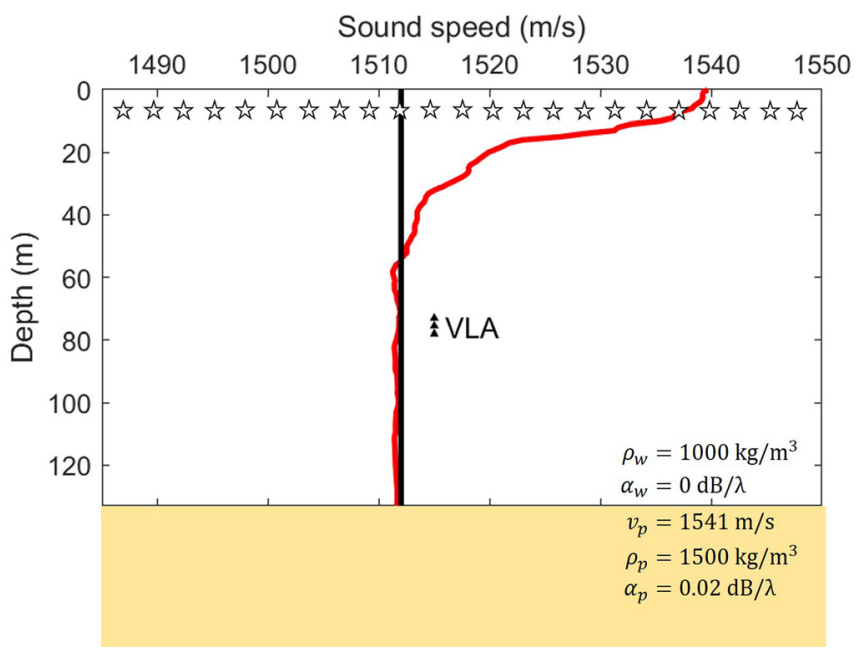

FIG. 3. (Color online) Model geometry for simulation. The sound speed profile measured from the Boundary'03 data, and the constant sound speed is considered. Noise sources (stars) are located everywhere on the surface. The vertical array consists of 32 hydrophones with spacing $0.18 \mathrm{~m}$, and the depth of the first hydrophone is $z_{1}=73 \mathrm{~m}$. 
(3) Multiply $\mathbf{L}(\omega)$ by $\mathbf{d}(\omega)$, a vector of independent, random complex numbers following a Gaussian distribution with zero mean and variance one to produce a single realization of the random process. Repeating for $L$ snapshots, this is written $\mathbf{b}_{l}(\omega)=\mathbf{L}(\omega) \mathbf{d}_{l}(\omega)$ for $l=1, \ldots, L$.

(4) Compute the sample noise covariance matrix by summing over $L$ realizations, $\mathbf{S}(\omega)=(1 / L) \sum_{l=1}^{L} \mathbf{b}_{l}(\omega) \mathbf{b}_{l}^{H}(\omega)$.

The auto-beam and cross-beam correlations are obtained according to Eq. (11), however, $\mathbf{C}$ is replaced by $\mathbf{S}$, and the number of snapshots $L=800$. The corresponding time-domain correlations are determined using Fourier synthesis based on Eq. (12) with frequency components computed every $1 \mathrm{~Hz}$ from 3500 to $4000 \mathrm{~Hz}$.

Figures 4-6 show the time domain auto-beam correlations, $c_{--}(\tau, \theta)$ and $c_{++}(\tau, \theta)$, and cross-beam correlation, $c_{-+}(\tau, \theta)$, for both refracting [Figs. 4(a), 5(a), and 6(a)] and Pekeris [Figs. 4(b), 5(b), and 6(b)] waveguides. In Figs. 4-6, although processing methods are different, the virtual head waves appear as the sequences of peaks at $11.1^{\circ}$ as the sound speed at the receiver $(1512 \mathrm{~m} / \mathrm{s})$ and in the seabed $(1541 \mathrm{~m} / \mathrm{s})$ is the same in both the refracting waveguide and Pekeris waveguide. However, the peaks are shifted in time in Figs. 4(a), 5(a), and 6(a) due to the refracting sound speed profile, as predicted by Eq. (10). As the water column sound speed in the Pekeris waveguide $(1512 \mathrm{~m} / \mathrm{s})$ is less than that in the refracting waveguide (mean $1525 \mathrm{~m} / \mathrm{s}$ ), the interval of peaks for the Pekeris waveguide (0.034 s) in Figs. 4(b), 5(b), and $6(\mathrm{~b})$ is greater than that for the refracting waveguide $(0.031 \mathrm{~s})$ in Figs. 4(a), 5(a), and 6(a) (the interval is inversely proportional to the water column sound speed as $\left.2 \int_{0}^{H}\left[v^{-2}(z)-s_{p}^{2}\right]^{1 / 2} \mathrm{~d} z\right)$.

The two peaks (away from the zero lag time region) at $\theta=90^{\circ}$ in the cross-beam correlation $c_{-+}(\tau, \theta)$ (Fig. 6) are passive fathometer returns. The peak on the left at $t_{1}=-0.096 \mathrm{~s}$ is the surface reflected wave, and the peak on the right at $t_{2}=0.079 \mathrm{~s}$ is the bottom reflected wave.

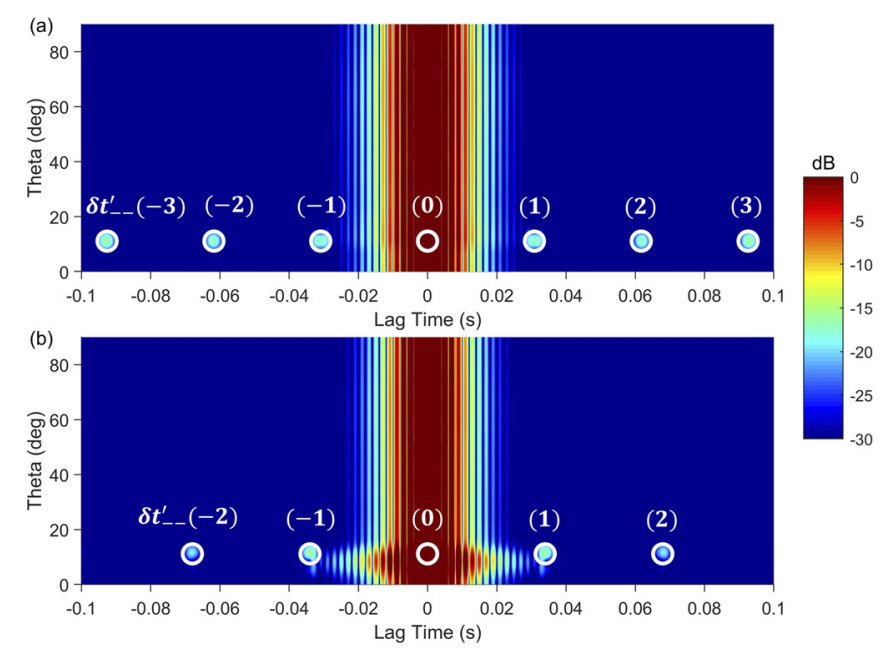

FIG. 4. (Color online) The time domain auto-beam correlation $c_{--}(\tau, \theta)$ from (a) the refracting waveguide and (b) the Pekeris waveguide in Fig. 3.

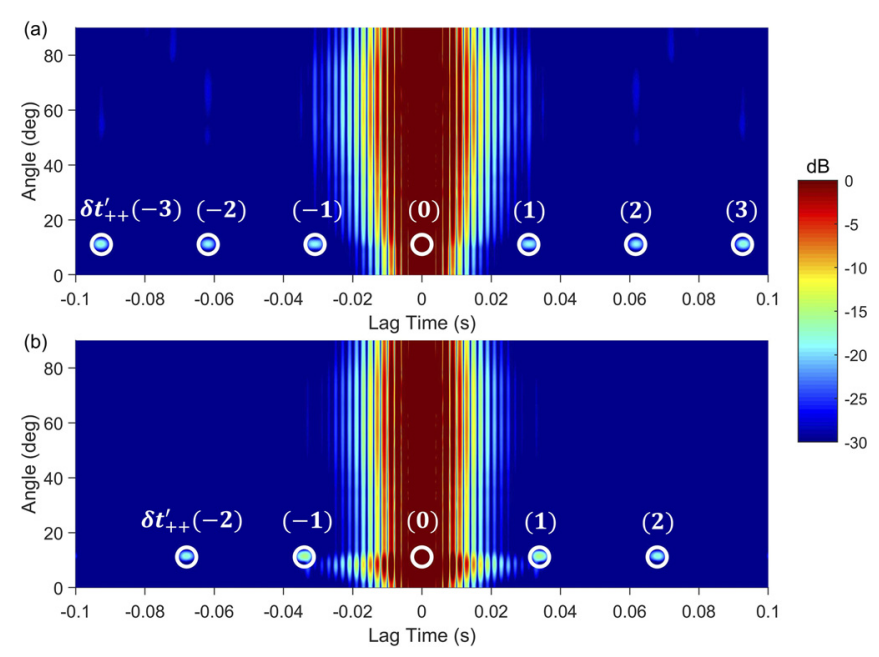

FIG. 5. (Color online) The time domain auto-beam correlation $c_{++}(\tau, \theta)$ from (a) the refracting waveguide and (b) the Pekeris waveguide in Fig. 3.

Figure 7(a) shows the angular dependency found by summing results in Fig. 6 over time $-0.1<\tau<-0.01 \mathrm{~s}$. The plot over the angle shows the same location of peaks at $11.1^{\circ}$ for both the refracting and Pekeris cases. Figure 7(b) compares the time series by making a line plot from Fig. 6 at the specific angle of $11.1^{\circ}$ for the two cases. Specifically, peaks from the refracting and Pekeris waveguides are almost the same at $\delta t_{-+}^{\prime}(1)$, while they are shifted at $\delta t^{\prime}{ }_{-+}(0)$ in Fig. 7(b). This phenomenon is explained with Eq. (15), which describes that $\delta t^{\prime}{ }_{-+}(0)$ (close to $-0.02 \mathrm{~s}$ ) and $\delta t^{\prime}{ }_{-+}(1)$ (close to $0.02 \mathrm{~s}$ ) correspond to the delay times between the surface and array and between the array and seabed, respectively. In the two waveguides, the array depth and water column depth are the same, and $\delta t_{-+}^{\prime}(0)$ and $\delta t_{-+}^{\prime}(1)$ are affected by the sound speed profiles above and below the array, respectively. By comparing the sound speed profiles in Fig. 3, it is shown that the sound speed profiles are quite different above the array (constant $1512 \mathrm{~m} / \mathrm{s}$

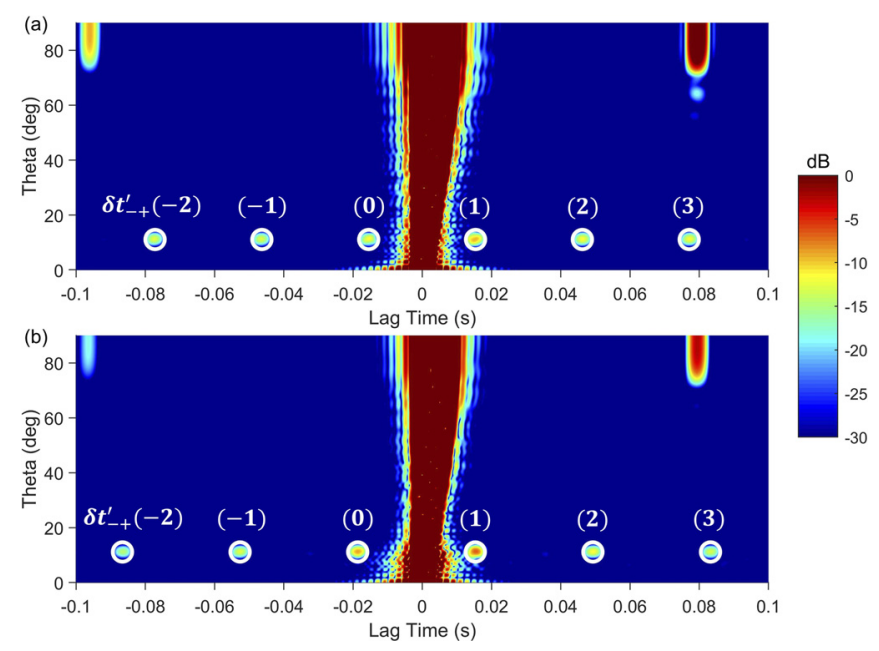

FIG. 6. (Color online) The time domain cross-beam correlation $c_{-+}(\tau, \theta)$ from (a) the refracting waveguide and (b) the Pekeris waveguide in Fig. 3. 

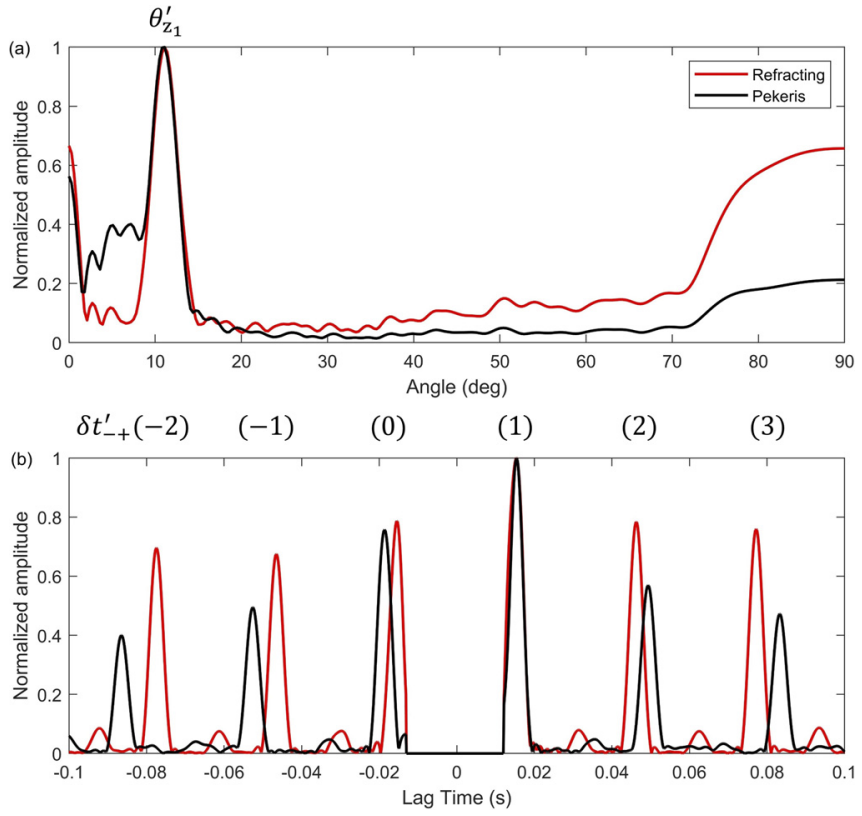

FIG. 7. (Color online) Angular spectrum and virtual head wave arrival structure extracted from Fig. 6. (a) Angular spectrum obtained by summing results in Figs. 6(a) and 6(b) over time $-0.1<\tau<-0.01$ s. (b) Time series at $\theta_{c}=11.1^{\circ}$ in Figs. 6(a) and 6(b).

for the Pekeris vs a mean of $1525 \mathrm{~m} / \mathrm{s}$ for the refracting) but almost the same $(1512 \mathrm{~m} / \mathrm{s})$ below the array.

Inserting the angle of arrival $\theta_{z_{1}}^{\prime}$ and travel times $\delta t_{-+}^{\prime}(0)$ and $\delta t_{-+}^{\prime}(1)$ into Eq. (14), the array depth $z_{1}$ and seabed sound speed $v_{p}$ in the refracting waveguide are determined as the values giving the minimum in the ambiguity surface; see Fig. 8. Figure 9 shows the inversion results of $H, z_{1}$, and $v_{p}$ for the Pekeris waveguide based on Eq. (18). Both inversions show good agreement with true locations.

However, if the sound speed is refracting but is assumed constant in the water column, then the inversion method has errors. For example, by inserting the virtual head wave

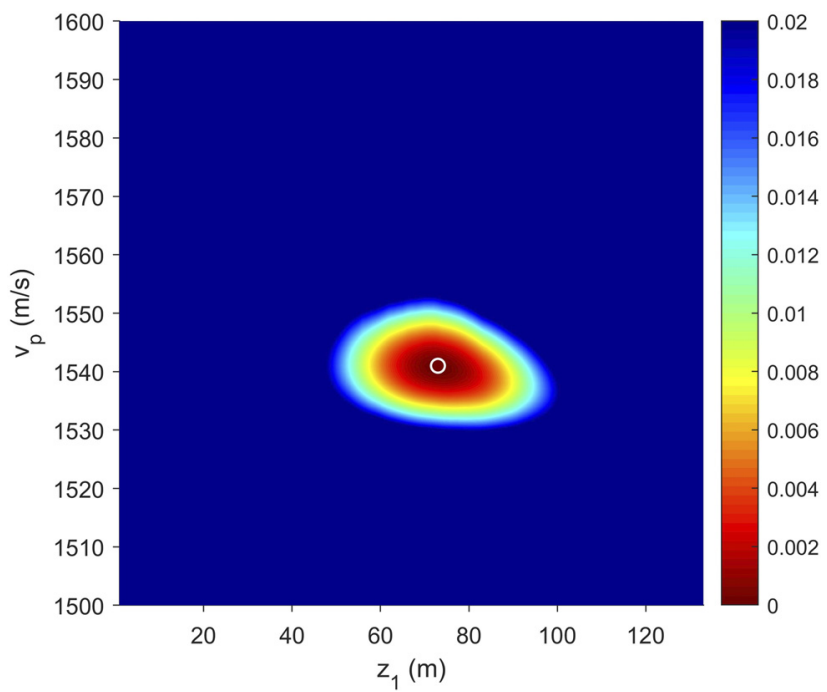

FIG. 8. Color online) The ambiguity surface [Eq. (14)] of seabed sound speed and array depth for the refracting waveguide with the true location $(O)$.
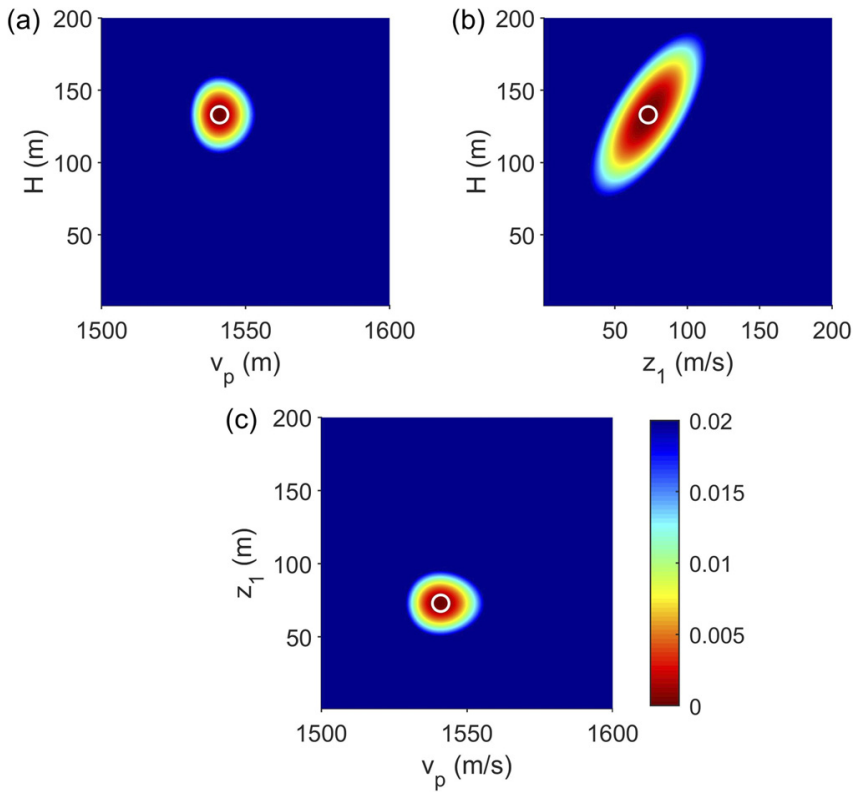

FIG. 9. (Color online) The ambiguity surface [Eq. (18)] of water depth, array depth, and seabed sound speed for the Pekeris waveguide with the true locations $(\bigcirc)$.

travel times in Fig. 6(a), which is from the refracting waveguide, into the inversion equation for the Pekeris waveguide [Eq. (18)], the refracting water column is treated as isovelocity, and the water depth and array depth are estimated with error; see Fig. 10.

\section{EXPERIMENTAL DATA}

The Boundary'03 experiment was conducted off the coast of Sicily, Italy in July, 2003. Acoustic data were collected on a free drifting array which had 32 hydrophones
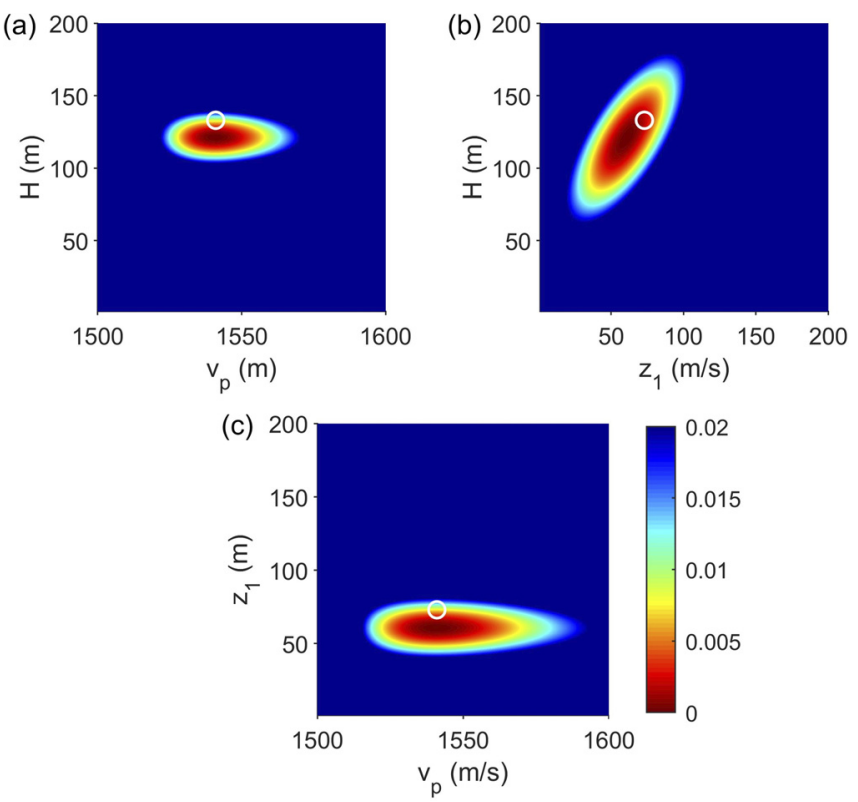

FIG. 10. (Color online) Same as Fig. 9, but the travel times and angle of arrival of the virtual head wave are from the refracting waveguide in Fig. 6(a). 
spaced at $0.18 \mathrm{~m}$, allowing for a maximum beamforming frequency (without aliasing) of $4.2 \mathrm{kHz}$. $^{7,9}$ The data considered here are in the frequency band of $3500-4000 \mathrm{~Hz}$ and were dominated by wind driven ambient noise. The wind speed during the measurements was $7 \mathrm{~m} / \mathrm{s}$. The array position was not recorded, but the depth of the first hydrophone was approximately $73 \mathrm{~m}$, and the water depth was about $133 \mathrm{~m}$. The sound speed profile is shown in Fig. 3, which is a typical summer downward refracting profile with the sound speeds of $1540 \mathrm{~m} / \mathrm{s}$ at the surface and $1512 \mathrm{~m} / \mathrm{s}$ near the seabed. The sound speed profile was taken half a month prior to the drifting array measurements and in a location near the initial deployment site (measured at 08:43 UTC July 9, 2003, while the data were taken at 18:11 UTC July 23, 2003).

The data were sampled at $12 \mathrm{kHz}$ and were Fourier transformed using a 4096 point fast Fourier transform (FFT). The total averaging time used to form the noise covariance matrix was $3.5 \mathrm{~min}$. In Fig. 11, the time domain auto-beam correlations [Figs. 11(a) and 11(b)] and crossbeam correlation [Fig. 11(c)] are shown with the band limited to $500 \mathrm{~Hz}(3500-4000 \mathrm{~Hz})$. Similar to the simulation results in Figs. 4-6, the virtual head wave arrivals are observed as a sequence of signals in time at a specific angle. The theoretical virtual head wave travel times are also indicated in Fig. 11. In all the panels of Fig. 11, the expected locations for the refracting profiles $(\Delta)$ match better with the experimental results than those predicted assuming a Pekeris profile $(\bigcirc)$.

The virtual head wave angles and travel times in the time domain cross-beam correlation $c_{-+}(\tau, \theta)$ can also be compared between the modeling and experimental results
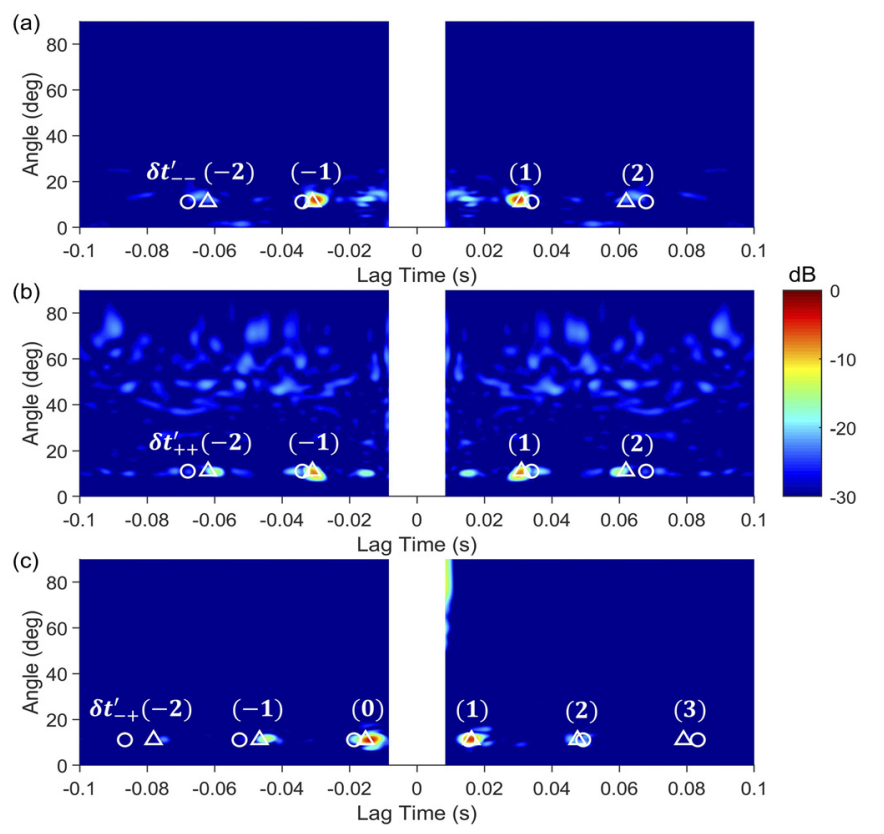

FIG. 11. (Color online) The time domain auto-beam correlations $\left[c_{--}(\tau, \theta)\right.$ in (a) and $c_{++}(\tau, \theta)$ in (b)] and cross-beam correlation $\left[c_{-+}(\tau, \theta)\right.$ in (c) $]$ using Boundary'03 data. The virtual head wave travel times from the refracting waveguide in Figs. 4(a), 5(a), and 6(a) ( $\Delta$ ) and the Pekeris waveguide in Figs. 4(b), 5(b), and 6(b) $(\bigcirc)$.
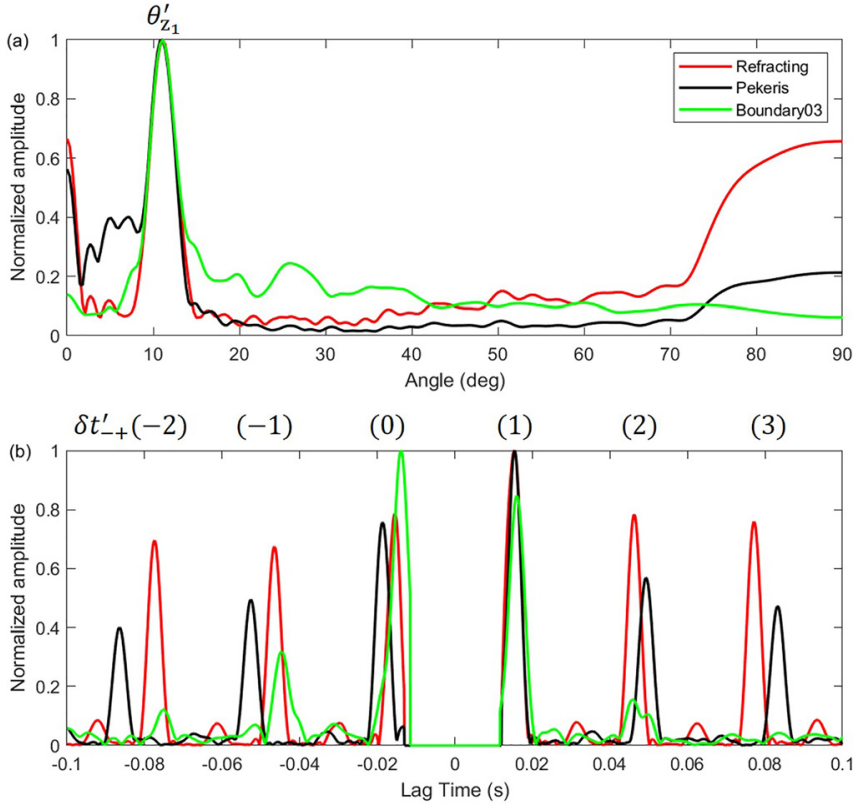

FIG. 12. (Color online) Angular and virtual head wave arrival structure extracted from Figs. 6 and 11. (a) Angular spectrum obtained by summing results over time $-0.1<\tau<-0.01 \mathrm{~s}$. (b) Time series at $\theta_{c}=11.1^{\circ}$.

using line plots in Fig. 12. Figure 12(a) shows the virtual head wave peaks after summing over the lag time from $-0.1<\tau<-0.01 \mathrm{~s}$. The agreement in angle is excellent for both models and data. As before, this is primarily because the sound speed profile is constant in all three cases between the array and seabed, and therefore does not introduce refraction. In Fig. 12(b), the virtual head wave travel times are shown for an angle of $11.1^{\circ}$. In contrast to the angular plot, the lag times are influenced by the refracting sound speed profile. The modeled travel times using the refracting (measured) sound speed profile are in much better agreement with the experimental results than those modeled using a constant (Pekeris) sound speed profile. The residual differences between the experimental and refracting model results are very likely due to errors in the sound speed profile, which was measured several weeks before the experiment.

Figure 13 shows the inversion result for array depth, $z_{1}$, and seabed sound speed, $v_{p}$, based on the travel times and angles of arrival of the virtual head waves. The array depth is estimated at $69 \mathrm{~m}$, which is $4 \mathrm{~m}$ less than the nominal value of $73 \mathrm{~m}$. The inverted seabed sound speed is $1540 \mathrm{~m} / \mathrm{s}$, which is consistent with other estimates of seabed sound speed in the experimental area. ${ }^{35}$

\section{DISCUSSION AND CONCLUSION}

The virtual head wave in a refracting ocean waveguide was discussed. It was shown that the virtual head wave between two receivers is produced by cross correlating ambient noise signals that contain the real, acoustic head wave. As opposed to the head wave, the virtual head wave can appear in the cross correlation between two vertically 


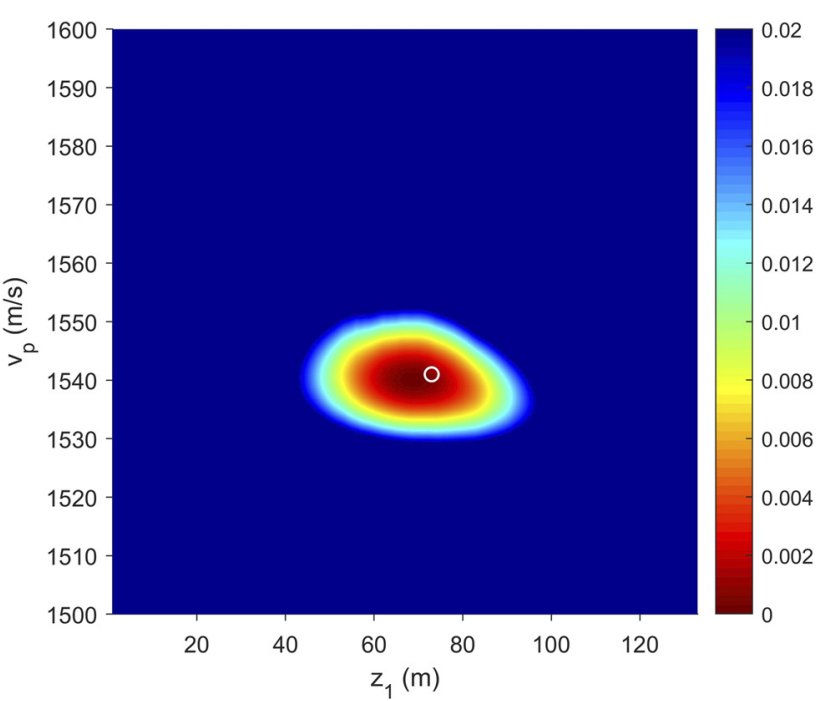

FIG. 13. (Color online) The ambiguity surface of array depth and seabed sound speed for the Boundary'03 data with expected location $(\bigcirc)$.

separated receivers. The virtual head wave travel times in a refracting waveguide were derived; they vary with water depth, array depth, and sound speeds in the water column and seabed. Simulations were used to verify the theoretically predicted virtual head wave arrivals in time and angle. It was shown that the virtual head wave arrival times can vary from those predicted, assuming a constant sound speed profile. While the angle of arrival can also vary in a refracting environment, it did not for the case shown here since the sound speed was constant between the array and seabed. However, the travel times were impacted by the refracting profile.

The Boundary'03 data confirmed the detection of the virtual head wave in a refracting waveguide. The travel times and angles of arrival of the virtual head waves were compared with the simulation results. The model result using the measured sound speed profile agreed with the data better than results modeled using a constant sound speed (Pekeris waveguide). This showed that the effects of water column refraction cannot be neglected.

By matching the travel times and angles of arrival of the virtual head waves, an inversion method was proposed to determine the geometric and environmental parameters for both refracting and Pekeris waveguides. The inversion method was applied to the measured Boundary'03 data and agreement was found between predictions and measurements to within experimental uncertainties associated with the measurements.

\section{ACKNOWLEDGMENTS}

This research was supported by the National Natural Science Foundation of China (Grant No. 11804222), the Young Elite Scientists Sponsorship Program by China Association for Science and Technology (CAST) (Grant No. 2018QNRC001), the Key Laboratory of Underwater Acoustic Environment, Institute of Acoustics, Chinese Academy of Sciences (Grant No. SHHJ-KFKT-1901), and the "Chen Guang project" supported by the Shanghai Municipal Education Commission and Shanghai Education Development Foundation.

\section{APPENDIX: INVERSION OF RECEIVER DEPTH $z_{1}: Y_{--}\left(z_{1}, v_{p}\right)$ VS. $Y_{-+}\left(z_{1}, v_{p}\right)$}

To demonstrate why the cost function $Y_{-+}\left(z_{1}, v_{p}\right)$ is more preferable for finding $z_{1}$ than $Y_{--}\left(z_{1}, v_{p}\right)$ when $v\left(z_{1}\right)$ varies slightly with $z_{1}$, we first get the derivatives of these two functions with respect to $z_{1}$. From Eq. (13),

$$
\begin{aligned}
\frac{\partial Y_{--}\left(z_{1}, v_{p}\right)}{\partial z_{1}}= & 2 \lambda\left[\theta_{z_{1}}^{\prime}-\arccos \left(v\left(z_{1}\right) / v_{p}\right)\right] \\
& \times \frac{1}{\sqrt{1-\left(\frac{v\left(z_{1}\right)}{v_{p}}\right)}} \frac{\partial v\left(z_{1}\right)}{\partial z_{1}} .
\end{aligned}
$$

When $v\left(z_{1}\right)$ varies slightly with $z_{1}, \quad \partial v\left(z_{1}\right) / \partial z_{1}$ $\approx 0, \partial Y_{--}\left(z_{1}, v_{p}\right) / \partial z_{1} \approx 0, Y_{--}\left(z_{1}, v_{p}\right)$ is independent of $z_{1}$, thus we cannot estimate $z_{1}$ by finding the minimum of $Y_{--}\left(z_{1}, v_{p}\right)$.

Similarly, from Eq. (14),

$$
\frac{\partial Y_{-+}\left(z_{1}, v_{p}\right)}{\partial z_{1}}=A \sqrt{\frac{1}{v^{2}\left(z_{1}\right)}-\frac{1}{v_{p}^{2}}}+\frac{\partial Y_{--}\left(z_{1}, v_{p}\right)}{\partial z_{1}}
$$

where $A=16 \int_{0}^{z_{1}} \sqrt{1 / v^{2}(z)-1 / v_{p}^{2}} d z+4 \delta t_{-+}^{\prime}(0)+4 \delta t_{-+}^{\prime}(1)$ $-8 \int_{0}^{H} \sqrt{1 / v^{2}(z)-1 / v_{p}^{2}} d z$. When $\quad \partial v\left(z_{1}\right) / \partial z_{1} \approx 0$, $\partial Y_{--}\left(z_{1}, v_{p}\right) / \partial z_{1} \approx 0$, Eq. (A2) is simplified as

$$
\frac{\partial Y_{-+}\left(z_{1}, v_{p}\right)}{\partial z_{1}}=A \sqrt{\frac{1}{v^{2}\left(z_{1}\right)}-\frac{1}{v_{p}^{2}}} .
$$

It is clear from Eqs. (A2) and (A3) that although $\partial Y_{--}\left(z_{1}, v_{p}\right) / \partial z_{1} \approx 0, \partial Y_{-+}\left(z_{1}, v_{p}\right) / \partial z_{1}$ is still a function of $z_{1}, Y_{-+}\left(z_{1}, v_{p}\right)$ is preferable for finding $z_{1}$ as it is contained in both travel time and angle contributions.

${ }^{1}$ O. A. Godin, M. G. Brown, N. A. Zabotin, L. Y. Zabotina, and N. J. Williams, "Passive acoustic measurement of flow velocity in the straits of Florida," Geosci. Lett. 1, 16 (2014).

${ }^{2}$ K. G. Sabra, P. Roux, A. M. Thode, G. L. D'Spain, W. S. Hodgkiss, and W. A. Kuperman, "Using ocean ambient noise for array self-localization and self-synchronization,” IEEE J. Ocean. Eng. 30(2), 338-347 (2005).

${ }^{3}$ P. Roux, K. G. Sabra, W. A. Kuperman, and A. Roux, "Ambient noise cross correlation in free space: Theoretical approach," J. Acoust. Soc. Am. 117(1), 79-84 (2005).

${ }^{4}$ L. A. Brooks and P. Gerstoft, "Green's function approximation from cross-correlations of $20-100 \mathrm{~Hz}$ noise during a tropical storm," J. Acoust. Soc. Am. 125(2), 723-734 (2009).

${ }^{5}$ C. H. Harrison and D. G. Simons, "Geoacoustic inversion of ambient noise: A simple method," J. Acoust. Soc. Am. 112(4), 1377-1389 (2002).

${ }^{6} \mathrm{M}$. Siderius and J. Gebbie, "Environmental information content of ocean ambient noise," J. Acoust. Soc. Am. 146(3), 1824-1833 (2019).

${ }^{7}$ M. Siderius, C. H. Harrison, and M. B. Porter, "A passive fathometer technique for imaging seabed layering using ambient noise," J. Acoust. Soc. Am. 120(3), 1315-1323 (2006). 
${ }^{8}$ C. H. Harrison and M. Siderius, "Bottom profiling by correlating beamsteered noise sequences," J. Acoust. Soc. Am. 123(3), 1282-1296 (2008).

${ }^{9}$ M. Siderius, H. C. Song, P. Gerstoft, W. S. Hodgkiss, P. Hursky, and C. H. Harrison, "Adaptive passive fathometer processing," J. Acoust. Soc. Am. 127(4), 2193-2200 (2010).

${ }^{10}$ P. Gerstoft, W. S. Hodgkiss, C. F. H. M. Siderius, and C. H. Harrison, "Passive fathometer processing," J. Acoust. Soc. Am. 123(3), 1297-1305 (2008).

${ }^{11}$ J. Traer, P. Gerstoft, and W. S. Hodgkiss, "Ocean bottom profiling with ambient noise: A model for the passive fathometer," J. Acoust. Soc. Am. 129(4), 1825-1836 (2011).

${ }^{12}$ J. Traer and P. Gerstoft, "Coherent averaging of the passive fathometer response using short correlation time," J. Acoust. Soc. Am. 130(6), 3633-3641 (2011).

${ }^{13}$ C. H. Harrison, "Doppler passive fathometry," J. Acoust. Soc. Am. 144(2), 577-583 (2018).

${ }^{14} \mathrm{~J}$. Gebbie and M. Siderius, "Head wave correlations in ambient noise," J. Acoust. Soc. Am. 140(1), EL62-EL66 (2016).

${ }^{15} \mathrm{M}$. Siderius, J. Li, and P. Gerstoft, "Head waves in ocean acoustic ambient noise: Measurements and modeling," J. Acoust. Soc. Am. 143(2), 1182-1193 (2018).

${ }^{16}$ O. A. Godin, N. R. Chapman, M. C. A. Laidlaw, and D. E. Hannay, "Head wave data inversion for geoacoustic parameters of the ocean bottom off Vancouver Island," J. Acoust. Soc. Am. 106(5), 2540-2551 (1999).

${ }^{17}$ M. V. Hall, "Measurement of seabed sound speeds from head waves in shallow water," IEEE J. Ocean. Eng. 21(4), 413-422 (1996).

${ }^{18}$ D. A. Bevans and M. J. Buckingham, "Estimating the sound speed of a shallow-water marine sediment from the head wave excited by a lowflying helicopter," J. Acoust. Soc. Am. 142(4), 2273-2287 (2017).

${ }^{19}$ J. W. Choi and P. H. Dahl, "First-order and zeroth-order head waves, their sequence, and implications for geoacoustic inversion," J. Acoust. Soc. Am. 119(6), 3660-3668 (2006)

${ }^{20}$ D. Mikesell, K. van Wijk, A. Calvert, and M. Haney, "The virtual refraction: Useful spurious energy in seismic interferometry," Geophysics 74(3), A13-A17 (2009).
${ }^{21}$ O. I. Lobkis and R. L. Weaver, "On the emergence of the Green's function in the correlations of a diffuse field," J. Acoust. Soc. Am. 110(6), 3011-3017 (2001).

${ }^{22}$ L. A. Brooks and P. Gerstoft, "Ocean acoustic interferometry," J. Acoust. Soc. Am. 121(6), 3377-3385 (2007).

${ }^{23}$ P. Roux, W. A. Kuperman, and N. Group, "Extracting coherent wave fronts from acoustic ambient noise in the ocean," J. Acoust. Soc. Am. 116(4), 1995-2003 (2004).

${ }^{24}$ K. G. Sabra, P. Roux, and W. Kuperman, "Emergence rate of the timedomain Green's function from the ambient noise cross-correlation function," J. Acoust. Soc. Am. 118(6), 3524-3531 (2005).

${ }^{25}$ K. Wapenaar, D. Draganov, R. Snieder, X. Campman, and A. Verdel, "Tutorial on seismic interferometry: Part 1: Basic principles and applications," Geophysics 75(5), A195-A209 (2010).

${ }^{26} \mathrm{~K}$. Wapenaar and J. Fokkema, "Green's function representations for seismic interferometry," Geophysics 71(4), SI33-SI46 (2006).

${ }^{27}$ R. Snieder, K. Wapenaar, and K. Larner, "Spurious multiples in seismic interferometry of primaries," Geophysics 71(4), SI111-SI124 (2006).

${ }^{28} \mathrm{~J}$. Li, P. Gerstoft, D. Z. Gao, G. F. Li, and N. Wang, "Localizing scatterers from surf noise cross correlations," J. Acoust. Soc. Am. 141(1), EL64-EL69 (2017).

${ }^{29}$ S. King and A. Curtis, "Suppressing nonphysical reflections in Green's function estimates using source-receiver interferometry," Geophysics 77(1), Q15-Q25 (2012).

${ }^{30} \mathrm{P}$. Shearer, Introduction to Seismology, 2nd ed. (Cambridge University Press, Cambridge, UK, 2009).

${ }^{31}$ L. M. Brekhovskikh, I. Lysanov, J. Lysanov, and Y. P. Lysanov, Fundamentals of Ocean Acoustics, 3rd ed. (Springer, Berlin, 2003).

${ }^{32} \mathrm{H}$. Schmidt, Oases 3.1 User Guide and Reference Manual (Massachusetts Institute of Technology, Cambridge, MA, 2004), available at http://acoustics. mit.edu/faculty/henrik/oases.html.

${ }^{33} \mathrm{H}$. Schmidt and F. B. Jensen, "A full wave solution for propagation in multilayered viscoelastic media with application to Gaussian beam reflection at fluid-solid interfaces," J. Acoust. Soc. Am. 77(3), 813-825 (1985).

${ }^{34}$ F. B. Jensen, W. A. Kuperman, M. B. Porter, and H. Schmidt, Computational Ocean Acoustics, 2nd ed. (Springer, New York, 2011).

${ }^{35}$ C. H. Harrison and P. L. Nielsen, "Geoacoustic inversion using multipath pulse shape," J. Acoust. Soc. Am. 122(6), 3268-3279 (2007). 